\title{
Serial Order Effects in Spelling Errors: Evidence from TV Dysgraphic Patients
}

\section{Niels O. Schiller ${ }^{-1}$, Jennifer A. Greenhall, Jennifer R. Shelton and Alfonso Caramazza}

Cognitive Neuropsychology Laboratory, Department of Psychology, Harvard University, Cambridge, MA 02138, USA ${ }^{1}$ Present address: Universiteit Maastricht, Faculty of Psychology, Department of Neurocognition, PO Box 616, $6200 \mathrm{MD}$ Maastricht, The Netherlands and Max Planck Institute for Psycholinguistics, PO Box 310, 6500 AH Nijmegen, The Netherlan

\section{Abstract}

This study reports data from two dysgraphic patients, TH and PB, whose errors in spelling most often occurred in th final part of words. The probability of making an error increased monotonically towards the end of words. Long wor were affected more than short words, and performance was similar across different output modalities (writing, typin and oral spelling). This error performance was found despite the fact that both patients showed normal ability to rep the same words orally and to access their full spelling in tasks that minimized the involvement of working memory. pattern of performance locates their deficit to the mechanism that keeps graphemic representations active for furthe processing, and shows that the functioning of this mechanism is not controlled or 'refreshed' by phonological (or articulatory) processes. Although the overall performance pattern is most consistent with a deficit to the graphemic buffer, the strong tendency for errors to occur at the ends of words is unlike many classic 'graphemic buffer patient whose errors predominantly occur at word-medial positions. The contrasting patterns are discussed in terms of different types of impairment to the graphemic buffer.

\section{Introduction}

Spelling errors of normal adults (e.g. Wing and Baddeley, 1980) as well as of brain-damaged patients (e.g. Caramazza and Miceli, 1990; Rapp and Caramazza, 1997) are not randomly distributed. Instead, they follow certain distributions, which can indicate where in the language production system the error occurs. For example, Wing and Baddeley (1980) investigated the spelling errors of normal subjects and found that slips of the pen were more likely to occur in the middle than at the beginning or end of words. Since their subjects wrote the words correctly at other times, the errors were assumed to have arisen after the orthographic representation in the lexicon had been accessed. Wing and Baddeley (1980) attributed the locus of the errors to the graphemic buffer, i.e. 'a working memory system which temporarily holds graphemic representations for subsequent, more peripheral processes (e.g. allographic conversion)' (Caramazza and Miceli, 1990, p. 257-8). The serial position effect of the spelling errors has been interpreted as resulting from interference between neighboring letters in the graphemic buffer (Wing and Baddeley, 1980). Since medial letters of a word have more neighbors than letters at the periphery of a word, they are more prone to being misspelled, resulting in a bow-shaped error distribution.
There are several neuropsychological studies repot patients who showed a similar bow-shaped distributio spelling errors. For instance, patient LB, studied Caramazza (Caramazza et al., 1987; Caramazza and Mi 1990), exhibited a bow-shaped distribution of errors in spelling of both words and non-words. The same distribu of errors was found in oral spelling, but oral repetition words was unimpaired, where LB repeated each word be writing it down. Thus, the (sublexical) phonological sys was unimpaired and LB's spelling deficit was localize the graphemic buffer level (see also Miceli et al., 1 1987; Posteraro et al., 1988; Hillis and Caramazza, 1 Kay and Hanley, 1994; McCloskey et al., 1994; Taintu and Caramazza, 1994; Jónsdóttir et al., 1996; Freed and Martin, 1999). Two patients (reported by Hillis Caramazza, 1989), ML and DH, however, showed a st deviation from the normal bow-shaped distribution of err In both cases, the distribution was bow shaped, but ske in opposite directions. Whereas ML's spelling errors occu primarily at the beginnings of words, $\mathrm{DH}$ showed an incre in errors towards the end of words. However, the ove spelling patterns found with both patients were compat with damage to the graphemic buffer. The authors propd

Correspondence to: Niels O. Schiller, Max Planck Institute for Psycholinguistics, PO Box 310, 6500 AH Nijmegen, The Netherlands. Tel: +31 24 352131 Fax: +31 24 3521213; e-mail: niels.schiller@mpi.nl or n.schiller@psychology.unimaas.nl 
that the skewed distribution of spelling errors is a variation of the normal bow-shaped pattern that is modulated by a mild hemispatial attentional deficit (neglect).

Caramazza proposed a set of criteria for identifying selective damage to the graphemic buffer (Caramazza et al., 1987). (1) Patients with this type of impairment should exhibit similar patterns of spelling errors for words and nonwords. (2) They should perform at comparable levels on a variety of tasks (e.g. written naming, writing-dictation, delayed copying, etc.) and across different oulput modalities (oral and written spelling, typing, etc.). (3) Their error patterns should not be affected by lexical factors such as word class, frequency and concreteness because temporary storage in the graphemic buffer is supposed to follow access to the orthographic representations in the lexicon. (4) The errors themselves should include substitutions, deletions, insertions and transpositions of letters. These types of errors would reflect the degradation of the spatially encoded, accurate graphemic representation of the intended word. Whole-word substitutions, how (except as these may result by chance from grapheme

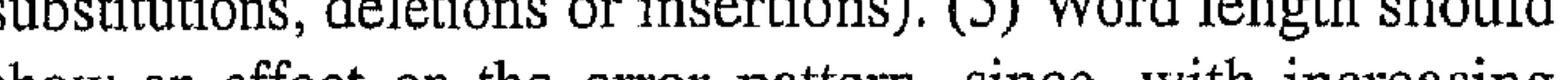
of and therefor the probaitity of makg a stling eros and therefore the

Katz (1991) reported a patient, HR, whose performance fifferent monotonically from the beginning to the end of a word. The athor accounted for this error distribution by chining that HR's impairment was due to a rapid decay of letter identity nformation in the graphemic buffer Letters that occured owards the ends of words had to be held longer in the buffer than letters at the beginning and were therefore more likely to be misspelled. In support of this hypothesis, Katz eported data from a backward spelling task in which lettes at the end of a word had to be produced before letters at the beginning (Katz, 1991). HR produced fewer errors on the etters at the end of the word than he did in normal forward spelling, supporting the 'decay-of-information' hypothesis. Clearly, HR's performance depended on writing directio (left-right versus right-left). A similar case, $\mathrm{CH}$, was reported by Bub (Bub et al., 1987).

Recently, Ward and Romani reported the case of patient $\mathrm{BA}$, who also showed a monotonically increasing seria position effect in her error distribution (like HR and the patients we are reporting in this paper) (Ward and Romani, 1998). BA produced initial letters more accurately than medial letters and medial letters more accurately than final letters. In comparison to previous interpretations, Ward and Romani (1998) argued that BA's serial position effect in the spelling errors was due to incomplete activation of the orthographic representations in the lexicon rather than damage to the graphemic buffer. Their patient, unlike HR (Katz, 1991), did not show the same error distribution in the backward spelling task as in the forward spelling task. For INOB, i.e. she made an error on the first spelled letter. This showed 政 abstract word form and not to the order in which she wrote the letters, prompting Ward and Romani to argue that this result does not support the hypothesis of a deficit to the graphemic buffer.

In this paper, we present data from patients $\mathrm{TH}$ and $\mathrm{PB}$, who show a "linear" serial position effect similar to patients $B A$ and $\mathrm{AR}$. TH's and PB's pattern of performance is important for (at least) two issues regarding spelling deficits: (1) understanding the contrasting error patterns displayed by patients (i.e. bow-shaped error pattern versus 'linear' error pattern) and (2) understanding the underlying nature of the deficit that results in the specific error pattern displayed by petien presented by Katz, 1991 and Ward and Romani, 1998). In addition, TH's and especially PB's performance may provide Information regarding the role of phonology in spelling. Jocessing could the pánstón (Jitus virtually unable to produce any spoken languge' (Ward and Ronat, 198, p. 191), TH and $\mathrm{NB}$ are fluent and repeat logical support can influence spelling performance.

\section{Case report 1: $\mathrm{TH}$}

$\mathrm{TH}$ is a 63-year-old, left-handed male who had a cerebrovascular accident in 1982. A CT scan performed 2 years post-onset revealed an old infarct in the territory of the left middle cerebral artery. Unfortunately, no photographic documentation of the $\mathrm{CT}$ scan is available. TH presents with mild lower right facial weakness, a plegic right upper arm and a paretic right leg. He also has reduced pin-prick sensation over the right side of his body. Visual fields are full on confrontation. Although TH has hemiparesis of the right side, he functions normally in daily life. He drives a car, works with a computer at home and uses e-mail. TH attended college for 1 year and worked for more than 40 enjoyed reading but is now retired. He reports that he always TH's working memory system is impaired. He has a digit span of only four digits forward and two digits backward. Digits were given at a rate of one per second. In the five digits forward condition, his response contained all target digits, but the order was not correct. TH showed no signs of neglect on a number of standard tasks such as drawing from memory, search tasks and line bisection. His speech is fluent and intelligible, and he can follow conversations. However, occasionally he makes semantic errors in oral (and written) Thanksgiving $\rightarrow$ Easter). His comprehension is normal to mildly impaired. He performed flawlessly (12/12 correct) in an auditory word-picture matching task, but showed mildly impaired performance (15/16, 94\% correct) in an auditory sentence-picture matching task. TH did not make any errors in auditory or visual lexical decision tasks (10/10 correct in each modality). His single-word and non-word repetition is unimpaired (50/50 correct).

- TH cannot read non-words aloud, indicating damage at some level of the grapheme-phoneme conversion process. Overall, his single-word reading is fairly good, but not perfect $(2059 / 2219=93 \%$ correct $)$. TH's reading performance is reported elsewhere (Rey et al., unpublished results).

In oral picture naming, TH exhibited mild impairments $(485 / 533=91 \%$ correct). For instance, on the Philadelphi Naming Test (Roach et al., 1996), he performed similarly to other patients of his age (see Ruml et al., 2000), but significantly worse than normal subjects (see Roach $e t$ al., 1996). His phonological output processes, however, were unimpaired, as indicated by his reading aloud of the same picture names $(429 / 435=99 \%$ correct) and by his perfect epetition (see above).

In written picture naming, TH performed worse (383/ $531=72 \%$ correct). He made two morphological and 24 semantic errors (e.g. duck $\rightarrow$ geese). In addition, he made many spelling errors (e.g. mushroom $\rightarrow$ rushmuck, televisio $\rightarrow$ televissor). Interestingly, he also made spelling errors on semantic substitutions (e.g. artichoke $\rightarrow$ caulflower, strawis $\rightarrow$ rasberrey). However, discounting spelling errors, his naming performance was similar for oral and written production.

TH does not seem to have specific grammatical problems but this aspect has not been studied in detail. He participated After research project from June 1998 to November 1999. his spelling abilities. During the testing period, his perg on ance was considered to be stable.

\section{General spelling abilities}

Across all tasks, TH spelled 1858 words (oral spelling writing to dictation, written picture naming, typing to dictation, spelling with letter cards). We will first give a genera overview of his spelling abilities and then discuss more specific tasks.

TH was given the Johns Hopkins University (JHU) Dysgraphia Battery (Goodman and Caramazza, 1987), which includes the following tests: part-of-speech, concreteness, egularity, phoneme-grapheme conversion probability (i.e. the probability of spelling a word correctly by applying nonlexical phoneme-grapheme conversion) and word length The phoneme-grapheme conversion probability test consists of a list of words that vary with respect to the probability with which a particular phoneme is transcoded into a particula rapheme. For instance, the phoneme $/ t$ is always transcoded as $\langle D$ in spelling, whereas /s/ can be transcoded as the graphemes $\langle s\rangle$ or $\langle c\rangle$, varying in probability. Table 1 displays TH's performance across all tasks and demonstrates hat he showed some effects of syntactic word class (partf-speech), with nouns and function words spelled better than verbs and adjectives $\left(\chi^{2}=10.6, P<0.05\right)$. He spelled concrete words better than abstract words $\left(\chi^{2}=7.0\right.$, $P<0.05$ ), and high-frequency words were spelled better than low-frequency words $\left(\chi^{2}=7.4, P<0.05\right)$. However, TH did not show an effect of regularity nor of phonemegrapheme conversion probability. Most importantly, TH showed a strong effect of word length, decreasing from $71 \%$ correct for four-letter words to only $36 \%$ correct for eightletter words.

TH's performance on writing pronounceable non-words was tested using two different lists of non-words. The first one contained non-words that were four or five letters in length, where $\mathrm{IH}$ spelled only $3 \%$ correctly $(2 / 70)$. However, in 53\% of the cases he got at least the first letter correct, showing that he could convert some phonological information into graphemes. For $47 \%$ of the non-words, TH made lexicalization errors, most of them being phonologically similar to the target (e.g. suft $\rightarrow$ soft or manch $\rightarrow$ ranch). The second list included 20 shorter non-words not exceeding thee letters $(10 \mathrm{CV}, 10 \mathrm{CVC}$, where $\mathrm{C}$ is consonant and $\mathrm{V}$ is vowel). TH performed much better on this second list. $\mathrm{He}$ spelled $50 \%$ of the non-words correctly; on $85 \%$ of the nonwords, he got the first letter correct, and on $75 \%$ even the first two letters were correct. This test showed that he could convert phonological information into graphemes, at least to some degree. Furthermore, the error pattern on non-words resembled the error distribution on words with more errors the end than at the beginning of words.

TH was also tested in a delayed copying task where he first looked at a string of letters printed in capital letters; the string was then covered and $\mathrm{TH}$ was asked to write it down in script form. This test was carried out to see whether knowledge about the spelling of a string influenced his length) pefornance The list of 62 items (4-7 letters in lengh) $52 / 62)$. Only two of his errors, TH scored $84 \%$ words ( $90 \%$ correct) per se that is responsible for his spelling ene lexical status per se th is resped to tor into script in the delayed copying task it may be posible that the error level ret possibility was tested in a dahyed copying tosk in which TH was asked to copy a new set of 40 words (5-7 letters in length) from printed capital letters into written capital letters. The results of this task were simila to his previous parformance in delayed copying: overall, TH hpevious performwords correcly and he made similar e. substitions, deletions, insertions, etc indicating that spelling problem is probably not due to impired allogaphic conversion. Furthermore, the letters he wrote were always well formed.

In general, TH was aware of his spelling errors, and he 
Table 1. TH's performance in various spelling tasks of the JHU Dysgraphia Battery

\begin{tabular}{|c|c|c|c|c|c|c|c|}
\hline Word list & Sublist & $\%$ correct & $n$ & $\chi^{2}$ & $P$ & Example target & Example error \\
\hline Part-of-speech & $\begin{array}{l}\text { Nouns } \\
\text { Verbs } \\
\text { Adjectives } \\
\text { Functors }\end{array}$ & $\begin{array}{l}82 \\
64 \\
43 \\
75\end{array}$ & $\begin{array}{l}23 / 28 \\
18 / 28 \\
121 / 28 \\
15 / 20\end{array}$ & 10.6 & $<0.05$ & $\begin{array}{l}\text { motel } \\
\text { learn } \\
\text { strict } \\
\text { while }\end{array}$ & $\begin{array}{l}\text { motol } \\
\text { leane } \\
\text { striqut } \\
\text { wild }\end{array}$ \\
\hline Concreteness & $\begin{array}{l}\text { Concrete } \\
\text { Abstract }\end{array}$ & $\begin{array}{l}71 \\
43\end{array}$ & $\begin{array}{l}30 / 42 \\
18 / 42\end{array}$ & 7.0 & $<0.05$ & $\begin{array}{l}\text { kitchen } \\
\text { moment }\end{array}$ & $\begin{array}{l}\text { kithen } \\
\text { memey }\end{array}$ \\
\hline Phoneme-graphem & $\begin{array}{l}\text { onversion probability } \\
\text { High } \\
\text { Low }\end{array}$ & $\begin{array}{l}77 \\
73\end{array}$ & $\begin{array}{l}23 / 30 \\
58 / 80\end{array}$ & 0.1 & $>0.10$ & $\begin{array}{l}\text { twin } \\
\text { fruit }\end{array}$ & $\begin{array}{l}\text { trim } \\
\text { friut }\end{array}$ \\
\hline Word length & $\begin{array}{l}\text { Four-letter } \\
\text { Five-letter } \\
\text { Sil-letter } \\
\text { Seven-letter } \\
\text { Eight-letter }\end{array}$ & $\begin{array}{l}71 \\
57 \\
64 \\
64 \\
36\end{array}$ & $\begin{array}{r}10 / 14 \\
8 / 14 \\
9 / 14 \\
914 \\
5 / 14\end{array}$ & 4.4 & $<0.05$ & $\begin{array}{l}\text { edit } \\
\text { igloo } \\
\text { fumble } \\
\text { absence } \\
\text { language }\end{array}$ & $\begin{array}{l}\text { abit } \\
\text { aggle } \\
\text { fulle } \\
\text { absene } \\
\text { langued }\end{array}$ \\
\hline Word frequency (c & $\begin{array}{l}\text { apsed across various } \\
\mathrm{HF}^{\mathrm{LF}}\end{array}$ & $\begin{array}{l}\text { sublists) } \\
67 \\
49\end{array}$ & $\begin{array}{l}74 / 111 \\
54 / 111\end{array}$ & 7.4 & $<0.05$ & & \\
\hline
\end{tabular}

Lexical factors, such as frequency, syntactic word class (part-of-speech) and concreteness affected TH's performance, indicating that mild damage to the lexical
stem is a contributing factor to his spelling performance. However, phoneme-grapheme conversion probability did not affect his spelling. Furthermore, his system is a contributing factor to his spelling performance. However, phoneme-grapheme conversion probability did not affect his spelling. Furthermore, his
spelling errors were not phonologically plausible (e.g. half $\rightarrow$ helf; idealist $\rightarrow$ ilealist). He made very few semantic errors (less than $1 \%$ ) i.e. categorically or

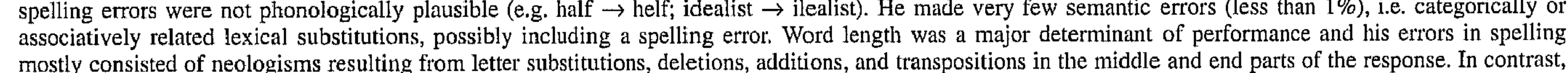
mostly consisted of neelogismms resulting f from letter substitutions, deletions, additions, and transpositions in the middle and end parts of the response. In contrast,
the number of lexical substitution errors in spelling was only 11 ( out of 1858 words $T H$ had to spelli; $0.6 \%$ ). However, even most of these 11 lexical substitutions the number of lexical substitution errors in spelling was only 11 (out of
maintained some visual similarity to the target, e.g. solve $\rightarrow$ folder.

mentioned this during spelling. However, when asked to correct his errors, he could not do so nor could he indicate where in the string the error(s) was (were) located. He often commented: 'That doesn't look right' or 'I know it's no right'. This is not surprising given the fact that $\mathrm{TH}$ performed flawlessly in lexical decision tasks (see above). Sometimes, however, he appeared unaware of his errors while writing. When he was asked to read a list of 68 words interspersed with 25 of his own non-word errors (taken from misspelled words of the JHU Dysgraphia Battery; see below), he recognized the misspelled strings as non-words, but could cond rear the non-words (10/25), he made a lexicelization $40 \%$ af came up wh a visully andor phonologically similar word (e. fush $\rightarrow$ fish). He was able to 1 ead the existing word in this list without any problem ( $96 \%$ correct), reflecting his overall good reading abilities.

\section{Specifying TH's spelling deficit}

The fact that he generally does not make semantic errors in reading, his inability to make complete use of phonemegrapheme conversion, and his lexical impairments including in written spelling and the part-of-speech and concretenes and semantic errors in written and spoken output, would classify TH as a 'deep dysgraphic' patient according to the criteria given in Bub and Kertesz (Bub and Kertesz, 1982). Actually, Bub and Kertesz's (1982) patient JC performed quite similarly to our patient $\mathrm{TH}$, except that $\mathrm{JC}$ was able to read pronounceable non-words whereas TH could not. TH is even more similar to the graphemic buffer patient VS studied by Nolan and Caramazza (Nolan and Caramazza, 1983). TH cem the Kenters impir, 1982 Nower and Com deficit This view is suppored by the foct that eren in written picture aning his semb pictire this vies is sis lexical item correctly, but when he tries to retrieve the

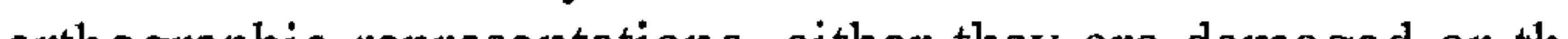
correctly retrieved orther corectly a the the spelling problem arises in transfering information $\mathrm{from}$ the orthographic representations into the oraphemic buffer, whether the graphemic buffer itelf is damased, or whether the deficit is in the transfer of information out of the graphemic buffer to more peripheral output processes, we cannot say. shows a relatively good overall reading performance ( $93 \%$ correct) compared to his relatively poor overall spelling pefaim the

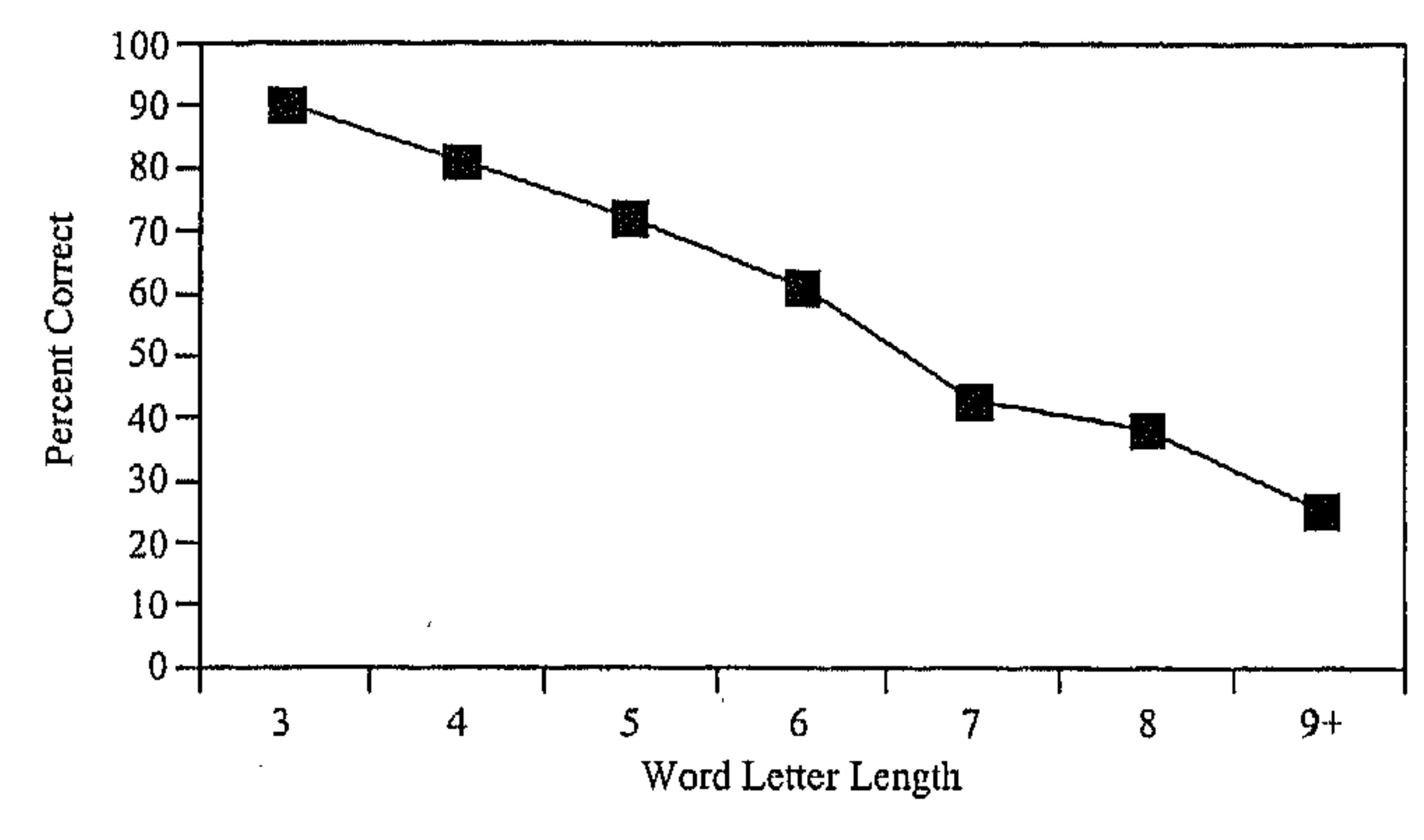

Fig. 1. Proportion of correct responses as a function of word length for TH.

Written spelling analysis

Altogether, TH spelled 1858 words. Figure 1 shows the proportion of correct responses as a function of word length, and it is quite evident that TH performs much better on shorter words as conpaned to longer words. Whereas he is over $90 \%$ correct on three-letter words and still over $80 \%$ correct on four-letter words, TH's performance falls to less than $30 \%$ correct on words that have nine letters or more. et al., 1987), who showed an even more pronounced wordet al., 1987),
length effect.

To investigate further the nature of TH's serial position effect in selling erors, new wo lists were devised to assess various factors thought to have an inflence do erial position fect in selling. The restls of his spelling performince on each of these below.

\section{Short versus long words}

The word-length effect reported above was found with the 'word-length list' (see Table 1) from the JHU Dysgraphia Battery. However, this list only contains 70 items. In order to assess TH's word-length effect further, we devised a new list of words, which varied word length across a broader range to test specifically whether TH would make more errors on long than on short words. This test includes a whole set of words that have at least eight letters, matched in frequency and word class to a set of shorter words.

Materials. Short words did not exceed two syllables $(M=1.6)$ and seven letters $(M=5.1)$; long words had at There were equally $(M=3.2)$ or eight letters $(M=8.7)$. classes in both sublists. Mean word frequency was lower for the short words (23 per million word forms) than for long words (34 per million word forms) as determined by CELEX (Baayen et al. 1995). There were 99 words in each of the two sublists. The complete list of 198 words was randomized and given to TH in a wiling-dictition task over three different testing session

Procedure. The procedure in this task and all of the subsequent written spelling tasks was as follows. The experimenter said the target word aloud, $\mathrm{TH}$ repeated it, and sen he wrote it down. hn the rare event hat TH repeated the word again until TH correctly repeated it. After his spelling attempt, TH was required to say the target word again

Results. Although word frequency was higher for the long words, TH made significantly more errors on the long word than on the short ones. He was correct on $64 \%$ of the short words (63/99), but only on $30 \%$ of the long words (30/99) $\left.\chi^{2}=22.2, P<0.05\right)$

To analyse the proportion of his spelling errors at each letter position across words differing in length, the distributio of errors was normalized according to the principles propose by Wing and Baddeley (Wing and Baddeley, 1980). This normalization procedure divides each word into five abstract letter positions (1-5). Each abstract letter position contain. one or more letters of the target word, depending on its length. The letters of the target word are assigned to the abstract letter positions in such a way that a symmetrical structure is maintained (see Caramazza et al., 1987 for detalls). The errors are calculated according to the criteria stated below and then divided by the total number of letters in a specific abstact letter position, thus yielding a proportional measier The engt

The error scoring followed the principles outlined in Caramazza and Miceli with some modifications (Caramazza cored 0.5 on to positions before and the insertion. Lets points to the 0.5 point to the oigin leter poition in the wo 025 points to the position before and after the inction 0.5 porch f the two positions from which the exchned letters riginate

Furthermore, the following general principles were applied. irst, target word and response were arranged in such a way the scoring segmental overlap between them. Secon a siven melled word The is wen werimal fo in different ways, the one with the least error points was chosen.

The normalized error distribution collapsed across shor and long words reveoled a monotonic increse in the relative proportion of error points from the first to the fouth positio $(13.3,20.2,25.0,27.1)$ and a slight decrease at the fifth position (228). TH was later asked to rend this list of words, which he did nearly perfectly $(196 / 198=99 \%$ correct $)$ demonstrating that he knew the words.

Discussion. TH's performance on a list of short versus long words supports the linear serial position effect in his spelling errors. Short words were spelled significantly better than long ones, and he made more spelling errors towards the end of words than at the beginning. TH was always correct when repeating the to be spelled word after his 
spelling attempt. In spite of this, he made many errors in spelling, especially on the long words. The fact that he could repeat the word after his spelling attempt implies that he rehearsed or always kept the target word in immediate memory. Yet, this phonological information did not improve his written spelling.

Morphologically simple versus complex words

One factor that was confounded with word length in the lis of short versus long words was the morphological complexity of words. Morphologically complex words, e.g. derived or inflected words, were on average longer than simple monomorphemic words. Therefore, the fact that TH s spelling performance was worse for long than for short words ma in fact have been a morphological effect. It could be that his morphological system is impaired such that complex word are more diffcult for him to write than simple words. To lest this hypothesis, we constructed another list of words, manipulating the factor of morphological complexity whil rying to keep all other factors constan

Materials. Altogether, there were 198 words in this list half of them simple (i.e. monomorphemic) with a mean length of 2.8 syllables and 7.0 letters, the other half complex (i.e. infected or derived), on average 2.8 syllables and 6.4 letters long. The number of words from different syntactic word classes was equal in both sublists and boh types of words had a wean frequency of occurence of 18 per on Restr. TH morphologically complex words (54/99). The nor ing followed the same pattern as in the previous spelling task: there was a linear ince from the begini to the enk of words (error proportions: $10.9,15.0,19.5,22.4$ the end of the first to the fifth normalized letter position, respectively). As with the previous list $\mathrm{TH}$ read these words nerly perfectly $(192 / 198=98 \%$ correct)

Discussion. In general, morphological complexity did no have an effect on TH's spelling performance. He performed slightly better on the complex than on the simple words. This shows that morphological complexity is not responsible for his marked word-length effect. The normalized erro distribution demonstrated that he made more errors toward the end of words than at the beginning. Thus, TH seems to display a similar, monotonically increasing error pattern a $\mathrm{HR}$ and BA (instead of the bow-shaped error pattern known from graphemic buffer patients such as LB or AS). We will discuss these contrasting error patterns in more detail in the General discussion.

Jverall spelling analysis

The normalized error distribution for all of TH's written selling enrors $(n=1817$; multiple spelling errors per wor were counted separately) on the whole corpus of 1858 word is depicted in Fig. 2D. The whole corpus includes the JHU and the two lists reported in the last two sections. As can be seen, the pattern of errors TH made increased monotonically from the beginning towards the end of words.

\section{Morphological boundaries}

Badecker reported the case of $\mathrm{DH}$, a graphemic buffer patient who showed a marked effect of morphological boundaries on the enror distribution for the spelling of morphologically complex words (Badecker et al., 1990). We looked this was also the case for $\mathrm{TH}$. To this end, the error distribution in misspelled compounds from a list including 62 compounds was analysed.

\section{Results and discussion}

TH did not show an effect of morphological boundaries in his spelling errors. His relative error proportions on the normalized positions were $5.3,6.9,15.3,15.7$ and 13.9 from the first to the fifth position for the first part of compounds. With respect to the second part of compounds, his relative entor proporions were 12.8, 10.8, 12.0, 16.5 and 18.6. In fact, when both parts were combined and analysed as a single (19, $29.4,367,37.6$ and 315). Unlike $\mathrm{DH}, \mathrm{TH}$ do not seem to be 3 . not seen to be sensitive to molphological boundaries of this point further a len we .

\section{Graphosyllabic structure}

Caramazza and Miceli suggested that graphemic representations consist of more structure than a linearly ordered string of graphemes (Caramazza and Miceli, 1990). The re-analysis of patient LB showed.that his spelling errors were constrained by graphotactic principles such as graphemic consonant, graphemic vowel and graphemic syllable. LB respected the $\mathrm{C} / \mathrm{V}$ status of the substituted letter in virtually all $(99.3 \%)$ letter substitution errors (736/741). Furthermore, his performance was significantly different on geminate and other CC clusters, indicating different graphosyllabic representations. clusters, indicating different graphosyllabic representations. principles as his errors violated basic phonological constraints such as the sonority sequencing generalization. On the basis of the error pattern found in LB, Caramazza and Miceli (1990) proposed a multi-tiered graphosyllabic orthographic lexical representation. The multidimensional structure of graphemic representations they suggested includes the following four tiers: a grapheme tier specifying the identity of the graphemes of a word, a quantity tier representing the quantity of the specified grapheme identities (e.g. single or double letter), a $\mathrm{CV}$ tier for the $\mathrm{C} / \mathrm{V}$ status of the grapheme and a graphosyllabic tier specifying the graphosyllabic bound-

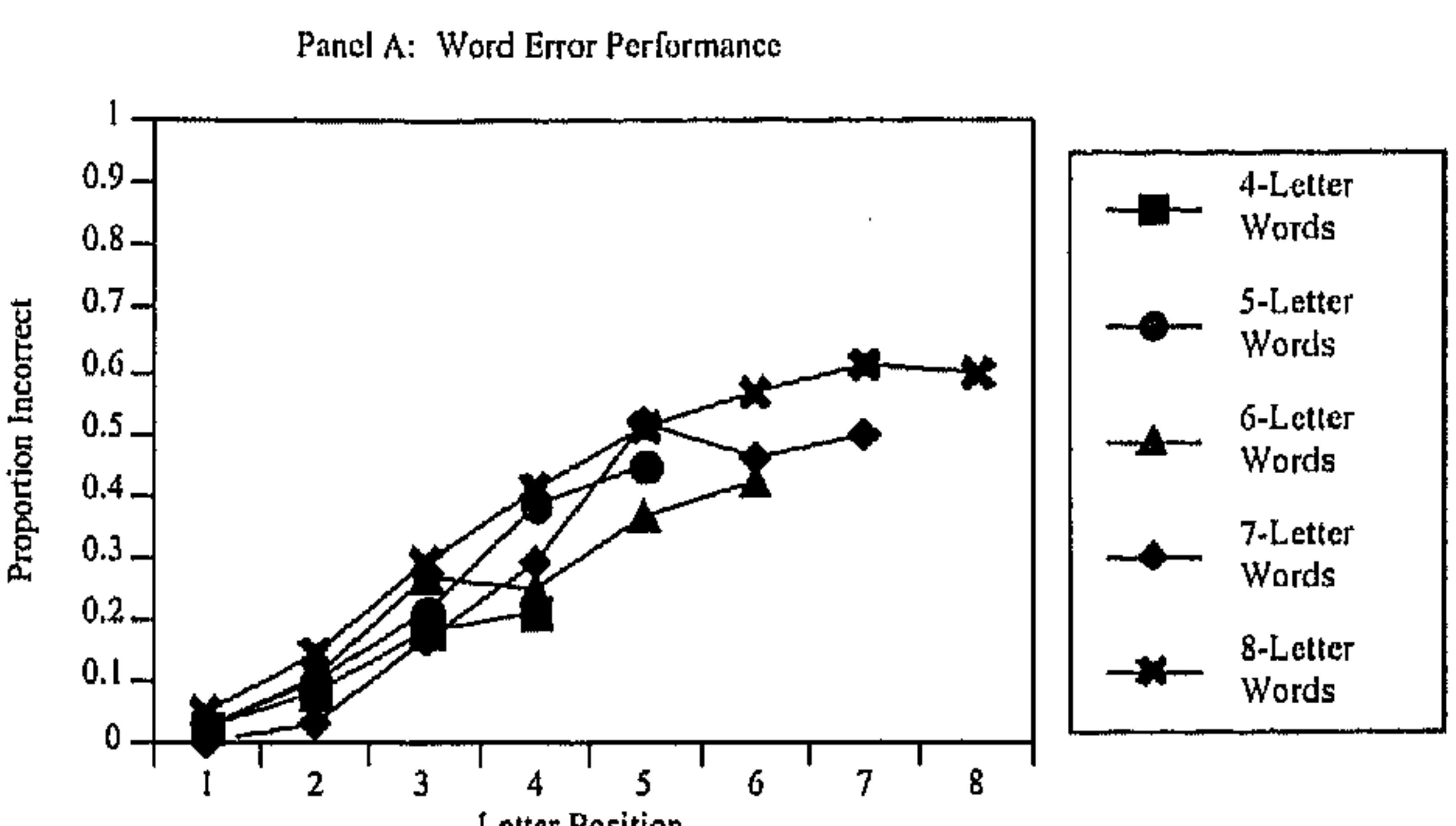

Pancl B. Non-word Broro Performance
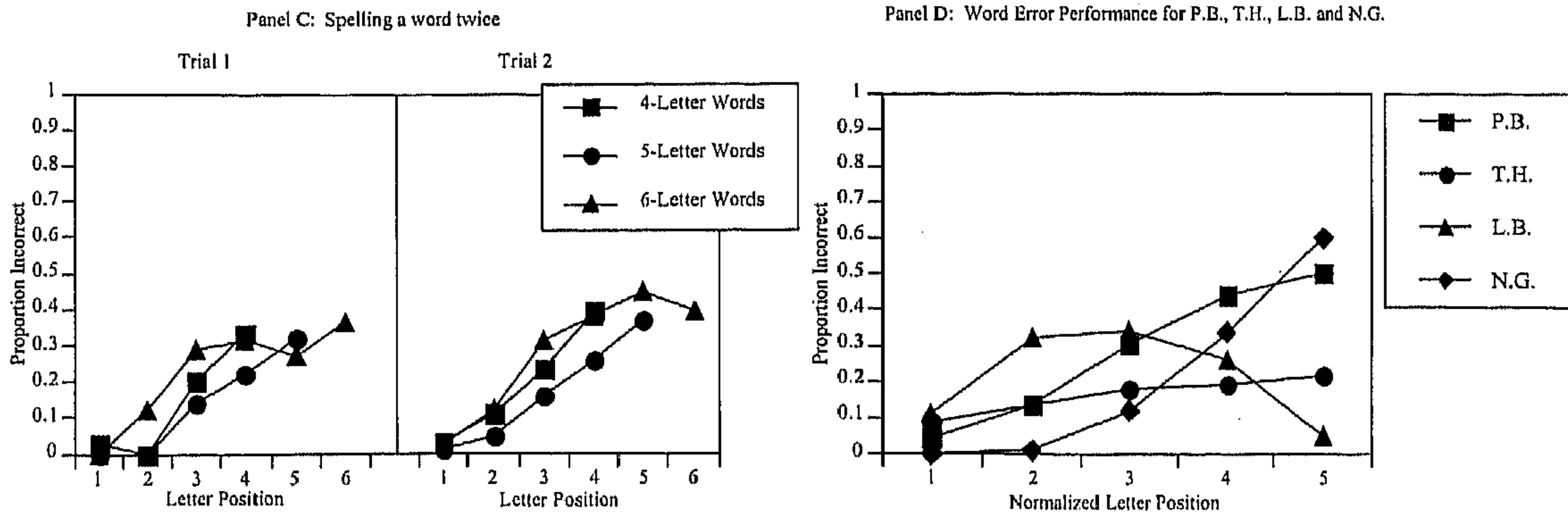

19. 2. Serial position performance in writing-to-dictation words and non-words. The following procedure was used in all writing-to-dictation tasks. First, the

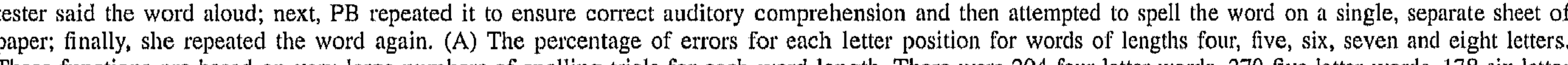
words, 107 seven-letter words and 135 eight-letter words. Very few errors were made for the first letter and errors increased for later letter positions. The distribution of spelling errors as a function of letter position in six-letter words in a control aphasic patient (MS) of comparable age and edcucalion to PB was (a) the target response by the subject when asked to spell a non-word. For example, FOIT could be spelled as FOIT, PHOOIT or FOYGHT or PHOIGHT, leading to four-, five-, six- or seven-letter length responses. The error total of eachl letter postition was sivided by the approximated number of words with letters at tha position performance in spelling a word twice. She was asted to spell a word, which was covered as she wrote it and then had to immedilatly rewrite it The profiles of performance for the two spelling trials are very similarr: she spells the beginning of the word much better than the end of the word, and errors

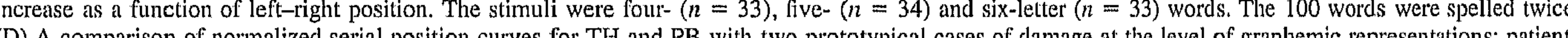
B and NG. Patient LB shows the inverted-U function commonly found for many dysgraphic patients with damage to the graphemic buffer. This profile of performance indicates damage to the graphemic representations held in the buffer. Patient $N G$ shows the classic word-centered profile of errors for patients with
word-centered neglect: errors occur on the left or right of center (depending on the site of lesion) of the word. This pattern of performance suggests damage to word-centered neglect: errors occur on the left or right of center (depending on the site of
a spatially specific mechanism for the allocation of attention to graphemic representations.

ries of a word. The analysis of JH's (Kay and Hanley, 1994) written spelling errors supported the view that consonants tho (191). This can be set as fither eviden (sor Carmazza and Miceli's (1990) notion of a multitien to letters (see also McCloskey et al but also

To investigate whether TH respects the double-letter status in his spelling errors, he was administered a letter quantity list consisting of four- and five-letter monosyllabic words some of which are spelled with a double letter, such as steel or skull. This list was administered to test whether or not his spelling errors honored graphosyllabic principles. TH's overall performance in this task was $80 \%$ correct On the double-letter words, he scored $88 \%$ correctly, and in 6 of his 11 errors he maintained a double letter in the error (e sneer $\rightarrow$ seeve, bleed $\rightarrow$ breeb, floss $\rightarrow$ fossol). Across all ther spelling tasks, TH made 112 errors altogether on words that contained a double letter, e.g. lettuce or kangaroo. In 76 of these errors (68\%), TH misspelled the target words with some sort of double letter. For instance, he misspelled lettuce as letten and kangaroo as kangeer. In contrast, $\mathrm{TH}$ inserted double letter into target words that did not originally contain double letter on 30 occasions only; considering insertion crrors alone, this amounts to a proportion of $11 \%$ of these errors. This indicates that graphemic representations possibly encode the double-letter status in a word and that TH still had access to this type of information despite his spelling deficit (Caramazza and Miceli, 1990; McCloskey et al., 1994; Micell et cl., 1995; Tainturier and Caramazza, 1996). To investigate whether TH respected the C/V status of the words that contrined substitution errors only. Of 291 substitu- 
tion errors, he respected the $\mathrm{C} / \mathrm{V}$ status of the substituted letter 251 times $(86 \%)$

Although TH does not preserve the $\mathrm{C} / \mathrm{V}$ and the doubleletter status in his spelling errors to the same degree as LB (or other patients in whom this has been investigated; Kay and Hanley, 1994; McCloskey et al., 1994), he does no substitute letters randomly. Furthermore, his spelling error are graphotactically legal, except for some very exceptiona cases like knife $\rightarrow$ fnive, and he tends to preserve lette length in his misspellings (see above). This supports the hypothesis that orthographic representations encode the C/N status, and thereby orthotactic constraints, as well as the double-letter status in words.

In summary, TH is a dysgraphic patient who showed marked effect of word length (more errors on long than on short words). His spelling errors include all kinds of segmenta errors, but hardly any whole-word substitutions. Although we cannot exclude damage to the lexical representations in the orthographic lexicon, TH's spelling deficit possibly involves the graphemic buffer. His spelling abilities were tested in different tasks and output modalities. For delayed copying and oral spelling, the error curves displayed a monotonic increase from the first to the fifth position, whereas for typing and backward writing he exhibited a bow-shaped error distribution. Most mportanlly, however, the error types we the sane across tasks, and enrors were not influenced

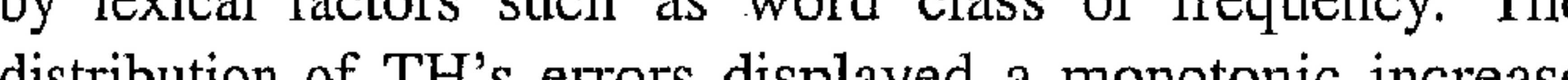
the the begining to the end of words. TH could repest without any problems the words he misspelled, cold repeat hat his phom less, he could not use the information from his phonological output buffer to improve his spelling difficulties. This dissociation is possibly due to the autonomy of phonologica and orthographic representations in the lexicon. However TH had problems spelling non-words because of his (partially) dysfunctional phoneme-grapheme conversion route. Therefore, it could be argued that this is the reason why he is unable to improve his spelling even though the phonological information is readily available to him. The second patien we present in this article, $\mathrm{PB}$, is very similar to $\mathrm{TH}$, except that her ability to spell non-words was better.

Case report 2: PB

PB is a 69-year-old, right-handed, highly educated woman who, as a consequence of a left-hemisphere stroke, has become hemiparetic, aphasic and dysgraphic. PB is a highly educated woman and has earned a BA in history, an MA in special education and was finishing her DEd (Doctor of Education) dissertation when she suffered a subarachnoid hemorrhage. In April 1992, a vascular MRI scan showed a superior/parietal left massive middle cerebral artery territory infarction with porencephalic changes and ventrichlar expanion. The frontal hom, occipital horn and the choroidal fissure were expanded, and the lenticulo-striate territory was not spared by the infarct. At the time of testing (1996-1997), PB was classified as a Broca's aphasic with poor comprehension for syntactically complex sentences. Her ability to repeat single words $(103 / 104=99 \%$ correct) and non-words $(33 / 34=97 \%$ correct) was excellent, if mildly apraxic. Her reading performance is mildy to moderately impaired. Most of her feading errors are vistally similar or morphologically related words ( $75 \%$ of all errors), but she also made occasional semanic errors. Her spelling performance, which is the focus of this paper, will be reported below in detail.

PB's spelling performance was also assessed with the JHU Dysgraphia Battery (Goodman and Caramazza, 1987). Overall, in writing to dictation, she spelled $39.3 \%$ or $351 / 894$ of the words correctly (excluding three-letter words), indicating that her spelling was severely impaired. Table 2 shows her performance across all tasks and demonstrates that PB showed an effect of syntactic word class with nouns and function words spelled better than verbs and adjectives $(P<0.01)$. She spelled concrete words better than abstrac words $(P<0.005)$ and high-frequency words better than low-frequency words $(P<0.001)$. Phoneme-grapheme conversion probability, however, did not influence her spelling behavior $(P>0.10)$. Most importantly, PB showed a marke word-lengh entect relatively high accuracy (93\%), her performance decrease to $T H$, Ore Oveall, $\mathrm{PB}$ and TH pefformed vey simil

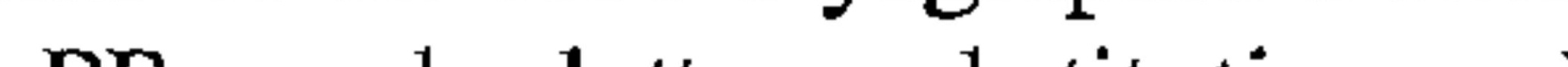

政, deletions, insertions and tran correctly (e. blast $\rightarrow$ blik mem $\rightarrow$ menting volpet $\rightarrow$ volchs). Detailed investigation of this feature of her performance revealed that the probability of correctly producing a letter decreased monotonically from the beginoduthe end of words. Her letters were consistently well formed. PB's ability to spell words orally could not be tested extensively becouse of an independent defitin letter nasing. PB's difficulty in naming letters was a source of considerable frustration to her, and she refused to be tested further on oral spelling. However, she was able to trace the letters correctly in the palm of her hand or on a table in front of her, and was able to spell with comprable performance to written spelling by arranging spelling cards.

PB was better able to spell non-words than TH. Whereas TH's ability to spell non-words correctly was limited to twoand three-letter non-words (50\% correct; see above) [he wa virtually unable to spell four- and five-letter non-word correctly (3\% correct only; see above)], PB was occasionally able to spell six-, seven- and eight-letter non-words correctly. Although her overall error proportion was higher for nonwords than for words (only $6 / 83$ or $7.23 \%$ correct), PB exhibited the same monotonic increase in error rates by length for non-words as for words, showing that the nature

- Table 2. PB's performance in various spelling subtests of the JHU Dysgraphia Battery

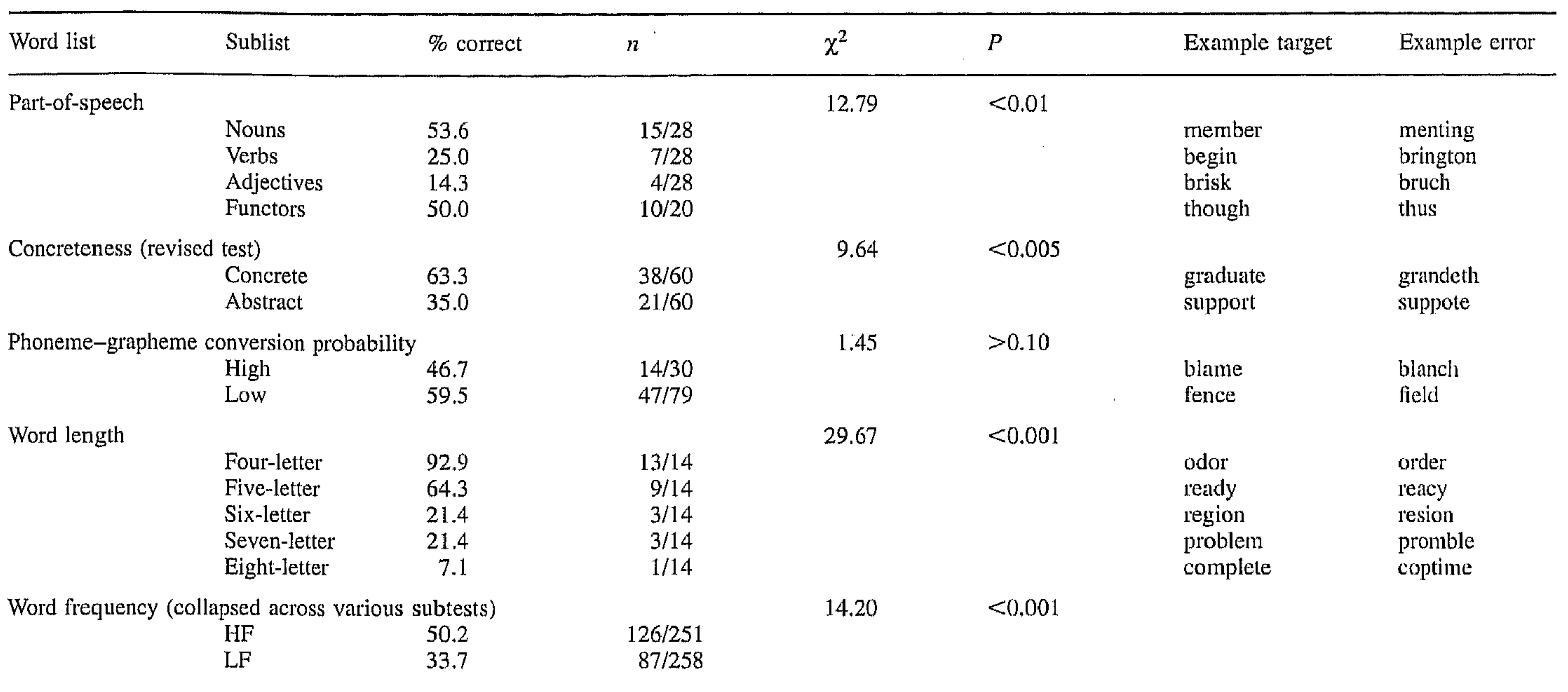

Frequency, grammatical class and concreteness (revised test) affected PB's performance, indicating that mild damage to the lexical system is a contributing
factor to her spelling performance. However, phoneme-grapheme regularity did not affect her performance in spelling words, and she did not make plonologite plausible spelling errors (e.g. writing chare for chair). She made very few semantic errors $(1.1 \%)$. Word length was a major determinant of performance and her errors in spelling words and non-words consisted almost entirely of neologisms (e.g. sleek $\rightarrow$ sleeght, travel $\rightarrow$ travi) resulting from letter substitulions,
deletions, addditions, and transpositions in the middle and end parts of the response. Her letters were consistently well formed. Her ability to spell words orally could not be tested extensively because of an independent deficit in naming letters. Thus, for example, when asked to spell wine, she traced all the letters correctly in the palm of her hand or on the table in front of her, but could not produce the name of the letter $\mathrm{N}$; and for the word the, she spontaneously traced
correctly all the letters in the palm of her hand, but was only able to name the letters $\mathrm{H}$ and the E. PB's difficulty in naming letters was a source of considerable frustration to her, and she refused to be tested further with this task. Nonetheless, the clear effect of word length on spelling performance and the types of

of her spelling deficit was not influenced by the lexical status of the stimulus per se (see Fig. 2A, B and D). Furthermore, er spelling of non-words demonstrated that she was able to anscode phonological into graphemic information. Together Worls correctly before, after and even during her splling werts corchly beere, after and eve dung her spelling thy Alhough the patien's (sublexical) output phonology is inse Al although her poneme-grapheme conversion is mosty (n)

PB's spelling deficit cannot be attributed to auditory misperception or forgetting of the stimulus since she almos invariably repeated the words correctly orally after she spelled them [she only made four repetition errors in 947 trials $(<1 \%)$, all of which were morphologically similar words] implying that her phonological buffer was intact-just as in lack of knowledge of or selective damage to the encl of words since she performed nearly flawlessly ( 97 and $94 \%$ correct for six- and eight-letter words, respectively) in modified spelling-dictation task minimizing the involvement of working memory (see Fig. 3A and B). In this task, she was required to fill in the missing letter in a word. By cies, PB performed far better than would be expected if she performed only using information based on trigram frequencies alone (six-letter word ABX yields an expected word ABX yields an expeted perom position, six-letter $X$ in expected perf poston, $42.6 \%$ with $X$ in the fifh position eight $21.6 \%$ with $X$ in the seventh position; eightleter word $A B X$ yields an expected performe of $423 \%$ with $X$ in the eighth position and eighteter word $A X B$ yields an expected performance of $41.3 \%$ with $X$ in the seventh position). When a similar tack was alministered to TH in November 1999 , he was correct on $82 \%$ of the trials (77/94 correct). Words were between seven and nine letters in length. Comp with his low proportion of correctly spetled words of the we line correct), this is a significant incer perfect. $P B$ 's good performance in this the was not merely due to a letter guessing strategy on the basis of the visual context provided by the word frame since she parformed similarly well in letter probe tasks ( $93 \%$ correct for the last letter) in which she was asked to decide, on separa trias whether a written letter was in the first two or last two positions of an aurally presented word (see Fig. 3C und D) This pattern of performance locates $\mathrm{PB}$ 's deficit to the 

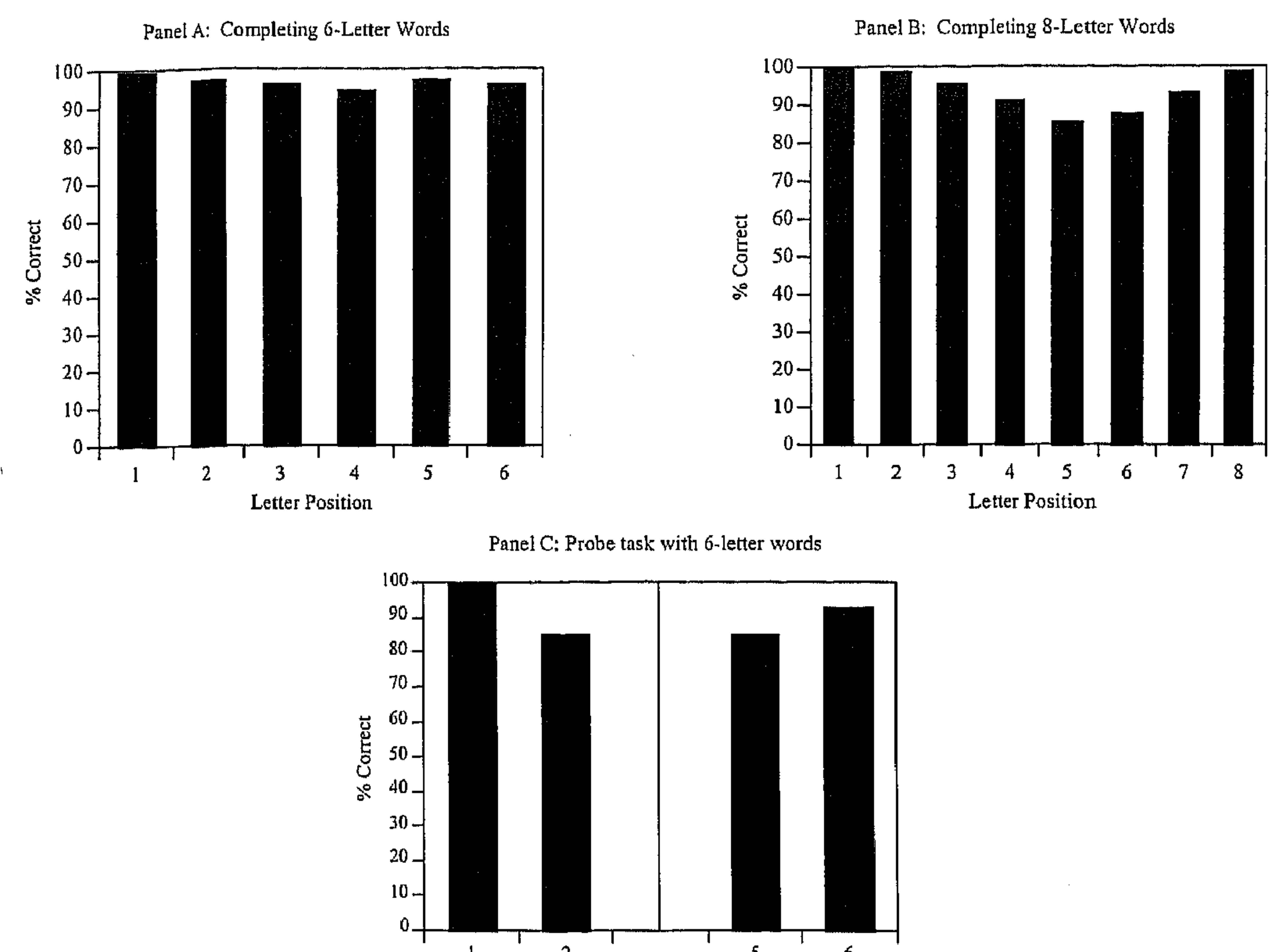

Letter Position

Fig. 3. Serial position performance for six- and eight-letter words in a modified writing-to-dictation task and for six-letter words in letter probe tasks. (A) and
(B) The results on tasks in which PB had only to produce the single missing letter in six- and eight-letter words PB perfors

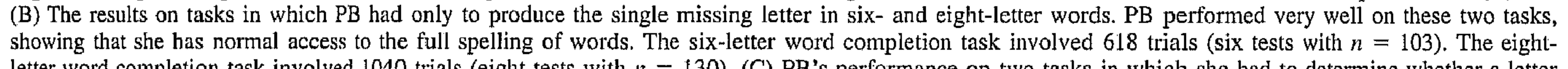

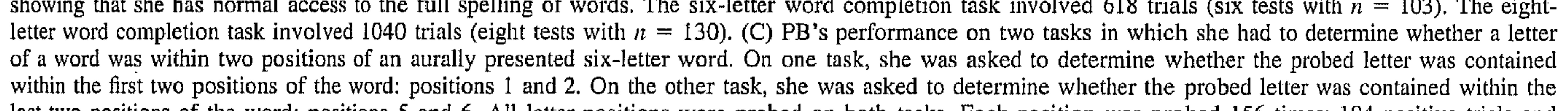
within the first two posititions of the word: positions 1 and 2 . On the other task, she was asked to determine whether the probed leter was contained within the
last two positions of the word: positions 5 and 6 . All letter positions were probed on both tasks. Each position was probed 156 times: 104 positive trials and
52 negative trials. Overall correct performance for each position was determined by averaging correct positive responses and correct rejections across the two tasks.

nechanism that keeps graphemic representations active for urther processing.

\section{Morphological boundaries}

In contrast to TH, PB showed an effect of morphological composition in her spelling performance. For compounds such as nightstand, for instance, she made fewer errors on the first few letters of the second part of the compound (e.g. $s$ and $t$ ) than on the last letters of the first part (e.g. $h$ and $t)$, even though the former occurred later in the word as a whole (see Fig. 4) $(n=54$ for both the first and second words within the compound, where words 5-7 letters in length were normalized to five letter positions). Comparing performances
for the last letter of the first word $(57.4 \%$ correct $)$ to performance on the first letter of the second word $(79.6 \%)$ yielded a significant difference $\left(\chi^{2}=6.18, P<0.025\right)$.

Discussion

PB's error distribution in compound words indicates that she could control the placement of graphemic information in the buffer (i.e. spelling the compound as two separate words),

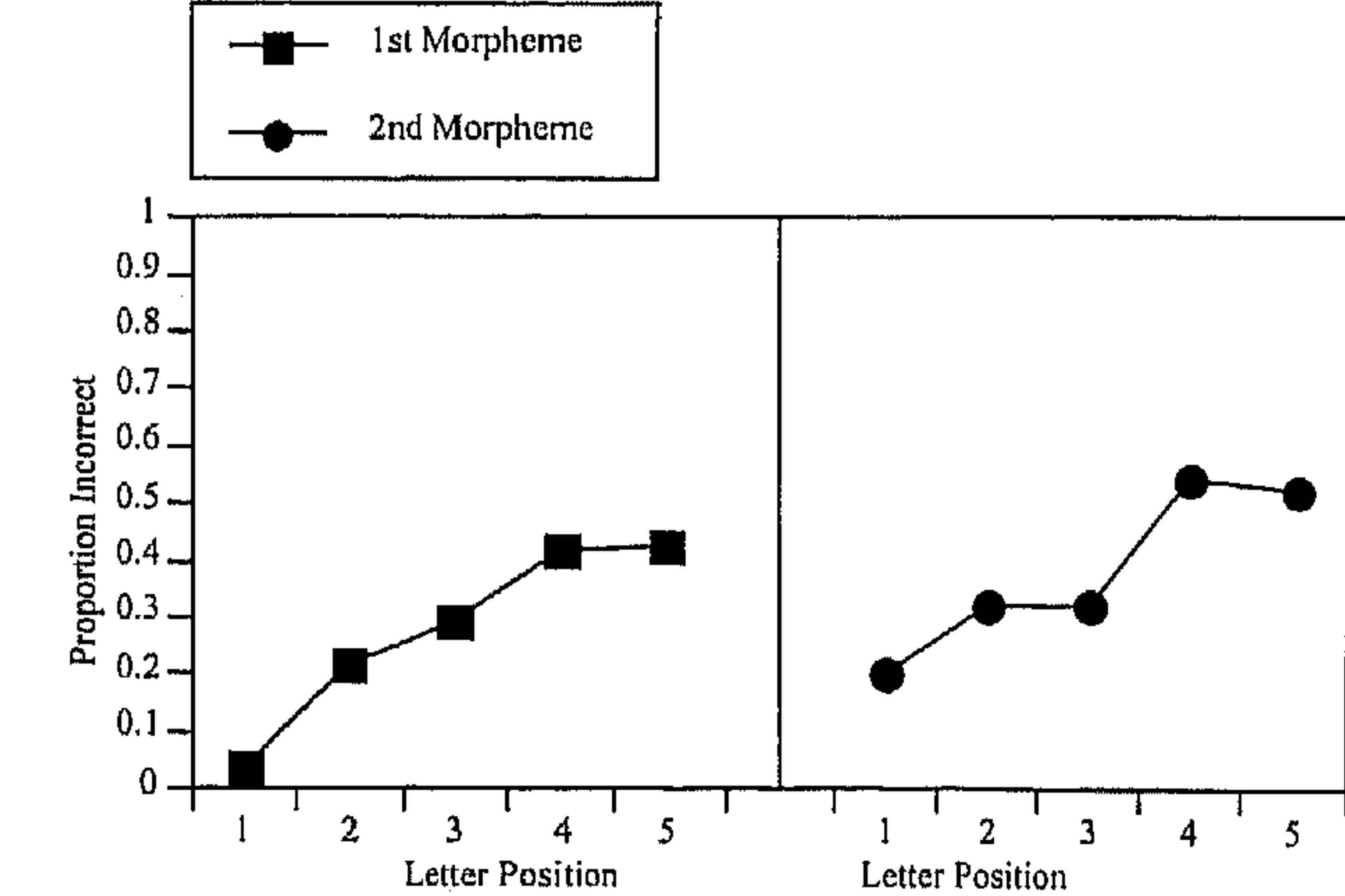

Fig, 4. Normalized serial position performance in spelling the two lexical

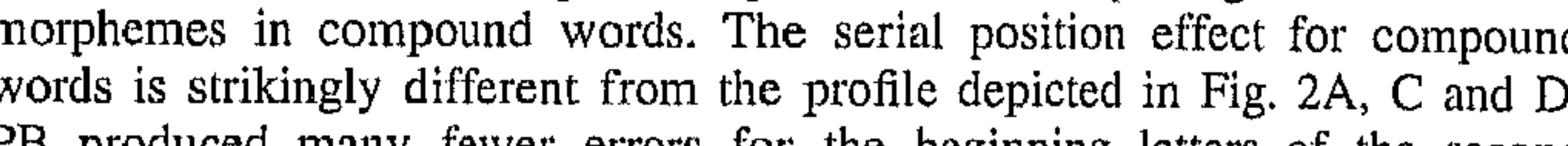
B produced many fewer errors for the beginning letters of the second coimpound than the end letters of the first compound. Morpheme length of
$5-7$ letters was normalized to five letters for the 54 compound words included
in the analysis $\left(\chi^{2}=6.18, P<0.025\right)$.

and the unit of control is the lexical morpheme. This is in contrast to TH, who did not show such an effect. Whether
this effect is due to a strategy based on meta-linguistic awareness (dividing words into their constituting morphemes and spelling one morpheme after the other) that some patients can use but others cannot, remains an open question.

General discussion

We have presented the cases of two dysgraphic patients, TH and $\mathrm{PB}$, who showed a strong word-length effect in their spelling errors, making more errors on long than on shor words. Furthermore, the probability of making a spelling error increased monotonically from the beginning to the end of words. Although both patients showed some small influences of lexical factors on spelling, their overall spelling performance satisfies the criteria given by Caramazza an therefore most closely resembles a deficit to a graphemic buffer, i.e. a working memory component that keeps graphemic information active for further output processing (Carm azzots al., 1987). The paten of TH's and PB's errors suggests that the longer phis information has to be TH and PB are very similar to BA (a patis sto be Ward and Ro are very silar to BA (a patient studied by Kat 1991). All four petients show an patient studied by errors from the beging to the end of wo la spelling we interpret TH's and likely due to a graphemic buffer deficit, athou to be most exclude damage to lexical orthographic representation. This deficit reflects an abnor or thy rapic decay rato leters at the end of the word are lost due to their position (i.e. items at the end require the most mainten hee pond would be most affected by an aberrant decay rate). Wand and Romani, however presented an alternative interprets an the linear increase in errors shown by their patient, BA. They arved that their patient suffered from incomplete BA. They of the abstract orthoraphic form and the incomplete activation had a greater impact on the ends of words than the beginnings of words. The main basis for Ward and Roman's preference for this interpretation over a graphemic buffer deficit was their patient's performance on a backward spelling task (i.e. the patient was given a word chair and had to spell it beginning with the last letter, riahc) $\mathrm{BA}$ did not show a linear increase in errors towards the 'end' of the word (e. riaXX), but instead made many errors on the last letter of the abstract word form (e.g. XXahc). Ward and Roman argued that if BA had a graphemic buffer deficit, she should have made more errors on the end of the string regardles of the order of the letters as they appear in the abstract word form (Ward and Romani, 1998).

The main problem with this argument is the lack of understanding of how the backward spelling task is carried out. In order to spell backward, access to information from the graphemic buffer is required, but we can imagine at least wo ways in which the task could be performed. The patient could generate a left-right representation (chair) and the scan right-left to spell the word backwards. Or, the patient could access the information by working repeatedly towards the end (ch, cha, chai, chair). In the latter case, no improvement would be expected on the end of the word since the spelling task would ulimately be the same as spelling in a forward direction. Thus, no improvement in performance on the ends of words when spelling backwards does not necessarily localize the deficit, since we can imagine at leas (x) ways in which a patient colld perform the lask. Moreover, BA's performance did not differ when spelling non-words, which suggests that she was retaining the representation of the segmental structure to be produced in the left-righ ashion and working towards the end of the item to be produced. The lack of understanding of how a backward spelling task is completed, and thus the uncertainty about What performance on this task is revealing about the underlying deficit, lead us to question the interpretation presented by Ward and Romani regarding their patient's deficit (Ward and Romani, 1998).

TH's and PB's deficits fit most clearly the pattern established as a graphemic buffer deficit, with one main difference. Although all of the reported patients presumably have a deficit at the level of the graphemic buffer and little or incer patlens contrast, as well as the end contrast dramalcally with the pallem reported for other 'Gaphenic buf riceli, 1990; Jónsótir et al 1996). It may

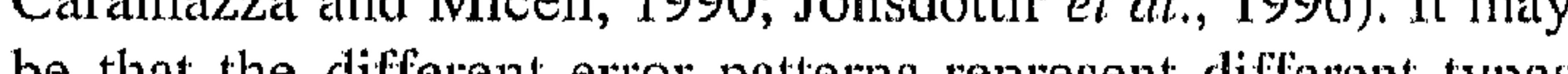
of that he difmer en the 'cophemic buffer' Patients who exhibit a bow-shaped

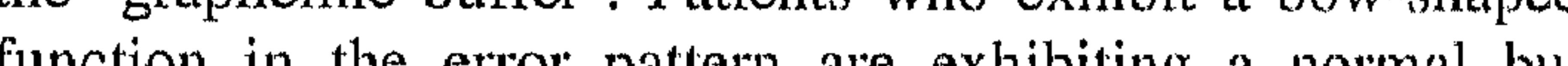
exacerbed patem of perforn 1980 for analysis of normal error patterns in spelling). Thus, these patients may suffer from a reluced level of activation in the lexical aystem that results in many spelling orions. This reduced lexical activation level decreas perforing overall, but does not interfere with the normal work

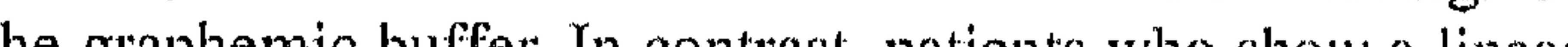
increase in erors towards the ends of words muy have a cecay defict the affects the graphenic bufer in such a way s to aler the actual functioning of this working a way system. These error potterns do not resember error pattery found with normal spellers and seem to reflect an abpormally apid decay of information such that information at the end of words is lost.

Recently, Houghton and colleagues (Houghton, 1990; Houghton et al., 1994; Shallice et al, 1995) proposed a pelling model that works without postating a (Eraphemic) buffer. 'This so-called 'competitive queuing' model is a connectionist model that comprises three layers of nodes: one layer of control nodes, one layer of nodes reprusenting the letters and one layer that functions as a "competitive filter'. The letter nodes are activated by weighted competive from a pair of control nodes whose aclivation patern varies with time. This pair of nodes consists of an initiote (I) node and an end (E) node. Ench letter node has weighted 
connections to both the I- and the E-nodes. Letter nodes with stong connections to the I-node will receive most activation at the beginning of the word (e.g. the initial letters) and those with strong E-node connctions (e.g. the final letters) will eceive most input towards the end of the word. The competitive filter identifies the most highly activated letter node at any given time, selects the corresponding filter node an inhibits the rest. The selected filter node then feeds inhibition back to the letter node, resulting in suppression of the node that was just selected previously.

At the beginning of the spelling process, only the I-node is active (and the E-node is inactive). As time passes, the I-node's activation decays while the activation of the E-node increases. This time-varying activation pattern allows different letters in the sequence to become maximally active different times. For the spelling of double (or geminate)

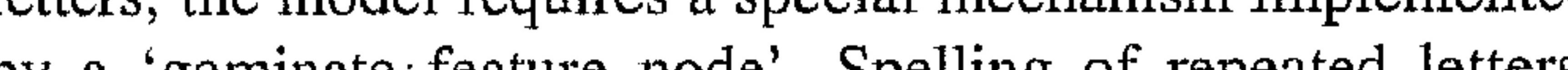

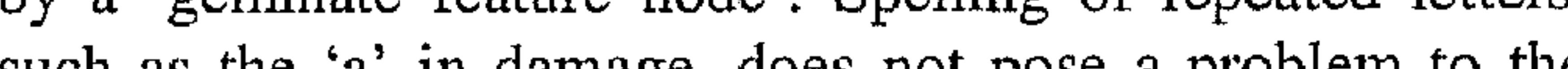
mole Even after selection and supression of the fist ' he letter ' 2 ' can be activated and selecter agin d ' $a$ ', connections to the E-node, which enables previously activated and suppressed letters to become activated again.

Could the competitive queuing model be used to accoun

for the patient data we presented in this study? Shallice damaged a competitive queuing model in such a way as to simulate the bow-shaped error distribution exhibited by raphemic buffer patients like LB and AS (Shallice $e$ t $a l$, 1995). However our patients show a markedly different erro pattern. Nevertheless, it might be conceivable that selective domage to the $\mathrm{E}$-node would result in a linear serial position effect of errors as exhibited by TH, PB and BA. This is ecause the activation of letters will decrease linearly ove the word because the strength of the weights from the I-node to the letter node layer gradually decreases. However, a pointed out by Ward and Romani (1998), lesioning of the E-nodes leads to the prediction of a particular spelling problem with repeated letters. To test whether this prediction could be supported by TH's data, we looked at his spelling performance in the 'word length' sublist of the HU Dysgraphia Battery. Excluding those words that had double letters or geminates, TH made eight errors on word including repeated letters and spelled 11 repeated letter words correct. The same was true for patient BA (Ward and Roman 1998): BA was no worse at writing words with repeate letters than words with no repeated letters. On the JHU Dysgraphia Battery's double-letter list, PB scored 48/98 $(49.0 \%)$ correctly for words without a double letter an $53 / 95(55.8 \%)$ correctly for words with a double letter, but his difference was not significant $\left(\chi^{2}=0.89, P>0.10\right)$. Thus, although selective damage to the E-node in a competiive queuing model could account for the linear increase in erers of patients like $T H$ and $\mathrm{PB}$, performance on repeated Ward is al (1998) - and the E-node could reproduce the spelling pattern of patient BA and yielded similar effects as selective damage the E-node alone.

The fact that $\mathrm{TH}$ and $\mathrm{PB}$ seem to suffer from a rapid decay of information in their graphemic buffer raises the issue of why patients do not refresh information in the graphemic buffer using phonological information. In fact, Jónsdótti tal. (1996) claimed that intact phonological processing can help keep the orthographic representations active while the patient is engaging in the sequential output process of spelling. The authors offered this as an explanation as to thy their graphemic buffer patient's overall performance 政 , presented by Caramazza and colleagues (Caramazza et al., 1987, Caramazza and Micell, 1990). The patients words before and after they wrote them down, indicating words before and after the wawe hen down, hdicating $n$ phonolo impired speling b havior, sugesting the god phomological information does not necessarily lead to imospelling performance, as Jónsdóttir et al have argued. But why would TH and PB not use this information if it were available? If TH and $\mathrm{PB}$ used lexical information to refesh information in the graphemic buffer, it could be done on a whole-word basis, wher then segmentally, and would on provide additional information to help them retain the fin letters of words. In addition, TH's non-word spelling was quite poor sugesting a fairly restricted ability to transcode phonological information into graphemic information. Thus, refreshing information in the graphemic buffer sublexically, which could be done segmentally, was not an option for TH. Therefore, regardless of how well he could retain phonological information, as demonstrated by his repetition of the target word after he attempted to spell it, TH could not use this information to improve his spelling performance. For PB, however, this was not the case. She could spell nonwords to some degree, indicating the (limited) ability to transcode phonological into graphemic information. Nevertheless, her error pattern was similar to TH's. In our view, this demonstrates that phonological and orthographic representations are autonomous (for further evidence with regard to the autonomy of orthographic representations, see Rapp et al., 1999).

A final contrast in performance between $\mathrm{TH}$ and another graphemic buffer patient (LB), who shows a bow-shaped error function, may provide additional information regarding the nature of the difference to the graphemic buffer. When TH was asked to read a list of short versus long words, he performed at a very high level (99\% correct, 196/198). In contrast, LB's deficit to the graphemic buffer impaired his reading (Caramazza et al., 1996), and LB's bow-shaped erro distribution was different from $\mathrm{IH}$ 's monotonically increasin curve. We hypothesized that $\mathrm{TH}$ suffers from an abnormally rapid decay of information in the graphemic buffer, wherea LB suffers from a reduced level of activation in the lexical system. Since reading is carried out in parallel (i.e. there i no scanning required), the temporal decay of information is not fast enough to have an effect on TH's reading performance. That is, the rapid decay of information hypothesi states that for output processes that occur very fast and in parallel, a graphemic buffer deficit will not show any effect, whereas in output processes that are slower and have to be carried out sequentially, an increasing distribution of the errors will be visible. PB was also only mildly impaired in reading, providing additional evidence that a graphemic buffer deficit resulting from rapid decay of information doe not affect output processes that occur in parallel, such as reading. Bow-shaped error distributions are presumably the result of a different underlying cause (see discussions above), and this cause also manifests itself in fast output processe like reading aloud. Recently, Hanley and Kay (1998) reported the case of a graphemic buffer patient, JH, who performed fine at reading words and hon-words. Unforth nately, however, they do not report the distribution pattern (bow-shaped or Future research on ' on the underlying causes that are responsible for the different error distributions.

Conclusion

In the cognitive and the neural sciences, a fundamenta distinction is drawn between the mechanisms that compute mental representations and the working memory systems or buffers that temporarily hold those representations for further processing. This distinction is supported by behavioral studies with neurologically intact and brain-damaged subjects and

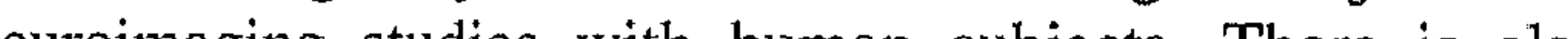
evidence for the finer-grained distinction between phonoogical and graphemic buffers that are used, respectively, in seaking and in spelling. Here we show that the mechen for keeping active abstract letter forms (granemes) for pelling $c a n$ be damaged independently of other aspects of the spelling process, and that the graphemic buffer functions autonomously of its phonological counterpart. The pation prononted in this paper, $\mathrm{TH}$ and $\mathrm{PB}$, suffer (mainly) from spelling impairment, where their spelling errors increase monotonically towards the end of a word, much like patients reported by: (Katz, 1991: HR; Ward and Romani, 1998: BA) in contrast to patients reported by: (Caramazza et al., 1987; LB; Jónsdóttir et al., 1996: AS). We have argued that two ypes of impairments might affect the graphemic buffer: one in which information decays abnormally rapidly $(\mathrm{TH}, \mathrm{PB}$, $\mathrm{BA}$ and $\mathrm{HR}$ ), resulting in errors increasing linearly towards the end of words, and the other in which noise in the system depresses the normal pattern (LB and AS), resulting in a bow-shaped error function. Both PB and TH correctly spell to dictation only the first few letters of words, despite showing normal ability to repeat the words orally and to access their full spelling in tasks that minimize the involvement of working memory. This pattern of performance locates thei deficit to the mechanism that keeps graphemic representations active for further processing, and shows that the functioning of this mechanism is not controlled or 'refreshed' by phonological (or articulatory) processes.

\section{Acknowledgements}

We would like to thank $\mathrm{TH}$ and $\mathrm{PB}$ for their cooperation during the testing. We also wish to thank Amir Zarrinpar and Kevin Shapiro for their assistance in part of the data analysis, Nina Silverberg for proof reading the manuscript and Gabriele Miceli for his advice on interpreting the medical records of TH. The research reported in this paper was supported by a grant from NIH NS22201. N.O.S. is now ( (KNAW).

References

Baayen RH, Piepenbrock R, Gulikers L. The CELEX lexical database CCD-
ROM). Philadelphia: Linguistic Data Consortium, University of

Pensylvania, 1995.
Badecker W, Hillisis, Carramazza, A. Lexicial morphlology and its role in the
writing process: Evidence from a case of accuired dysgranthia. Cognnition 1990; 35: 205-43. Bub D, Kertesz A. Deep agraphia. Brain and Language 1982; 17: 146-6.5.
Bub D, Black S, Howell J, Kertesz A. Damage to inpul and output buffers what's a lexicality effect doing in a place like unat? In: Keller E. Gopprik M, editors. Motor and sensory processes of language. Hillsdilite, NJ: amazza A, Miceli G. The structure of grayphemic representations. Cognition

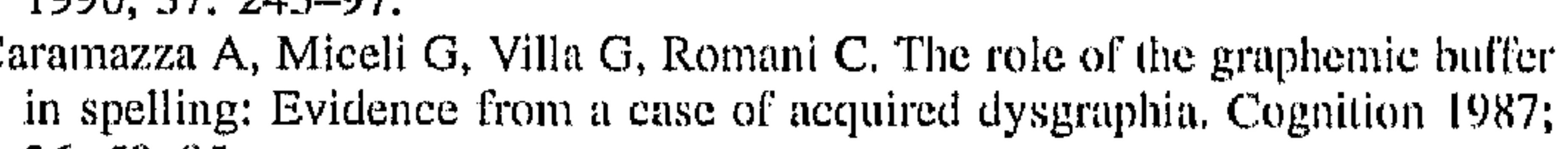
26: 59-85.

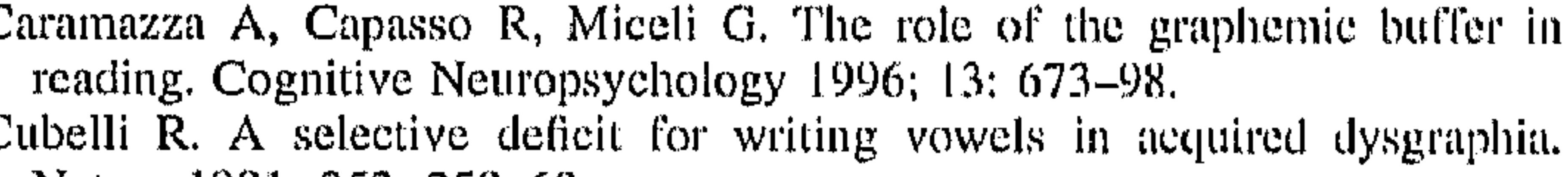
Nature 1991; 353: 258-60.
Freedman M, Martin RC. Persisting letter activation in spelling and implications lor the graphemic buffer hypothesis. Abstracts of the Psychonomic Society 1999; 4: 10.
Goodman RA, Caramazza A. The Joluns Hopkins University Dysgrayhhia Goodman RA, Carramazzia A. The Jolnns Hopkins University Dysgrath
Battery. Baltimore, MD: Jolnns Hopkins University, 1987. Hanley JR, Kay J. Does the graphenic buffer play a role in readling? Cognitive Neuropsychology 1998; 15: 313-8.
Hillis AE, Caramazza. A. The traphemic buffer and antentional mechanissms.
B

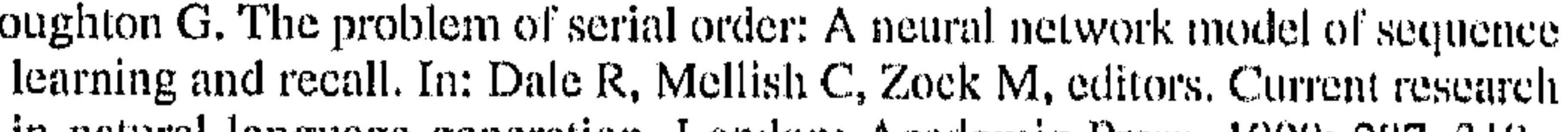
In natural language generation. London: Acadcic Press. 1990: 287.319 .

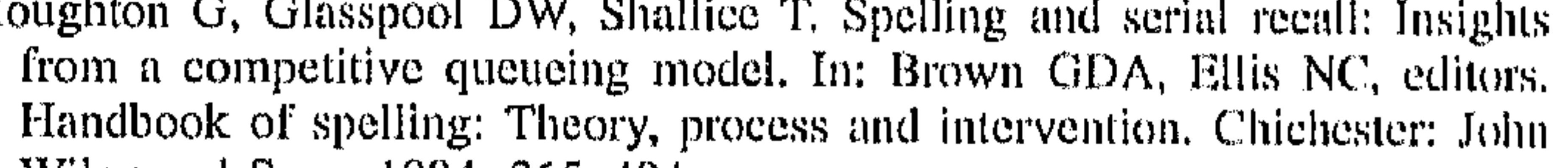
Wiley and Sons, 1994: 365-404

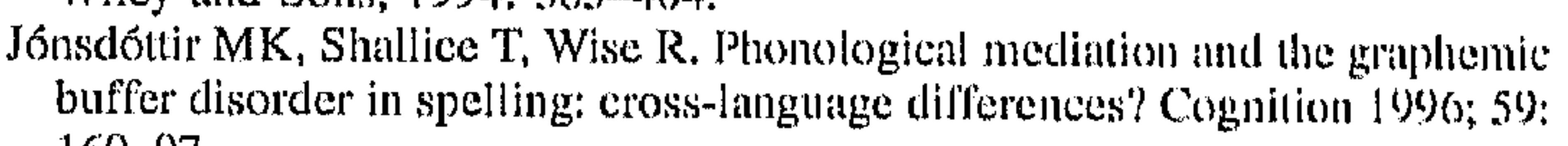
169-97.
Katz RB Limited retention of information in the graphemic buffer. Cortex Kay J, Hanley R. Periphcral disorter of spelling: The role of the graphlemice
buffer, In: Brown GDA, Ellis NC, edititors. Hanndhook of spelling: Theorry.

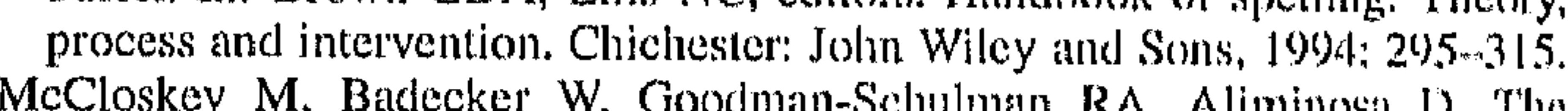

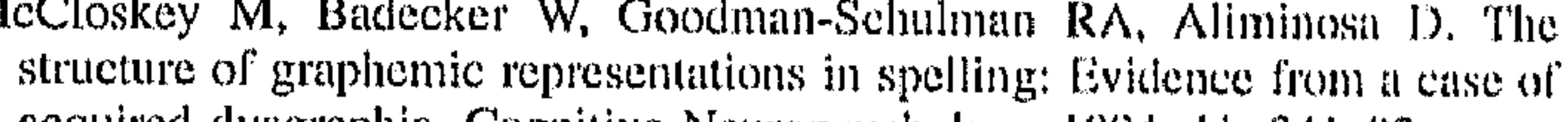

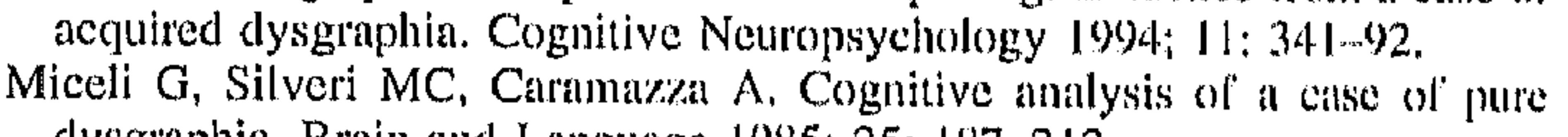


Miceli G, Silveri MC, Caramazza A. The role of the phoneme-grapheme conversion system and of the graphemic output buffer in writing. In: Coltheart M, Sartori G, editors. The cognitive neuropsychology of language. London: Lawrence Eribaum, 1987: 235-52.

Miceli G, Benvegnù B, Capasso R, Caramazza A. Selective deficit in processing double letters. Cortex 1995; 31: 161-71.

Nolan KA, Caramazza A. An analysis of writing in a case of deep dyslexia. Brain and Language $1983 ; 20$ : 305-28.

Posteraro L, Zinelli P, Mazzucchi A. Selective impairment of the graphemic buffer in acquired dysgraphia: A case study. Brain and Language 1988; 35: 274-86.

Rapp B, Caramazza A. From graphemes to abstract letter shapes: Levels of representation in written spelling. Journal of Experimental Psychology: Human Perception and Performance 1997; 23: 1130-52.

Rapp BC, Boatman D, Gordon B. The autonomy of lexical orthography: Evidence from cortical stimulation. Abstracts of the Psychonomic Society $1999 ; 4: 82$.

Roach A, Schwartz MF, Martin N, Grewal RS, Brecher A. The Philadelphia Naming Test: scoring and rationale. Clinical Aphasiology 1996; 24: 121-33.

Rey A, Schiller NO, Caramazza A. Grapheme-phoneme conversion in a phonological dyslexic patient. In preparation.

Ruml W, Caramazza A, Shelton JR, Chialant D. Testing assumptions in computational theories of aphasia. Journal of Memory and Language 2000; 43: $217-48$.

Shallice T, Glasspool DW, Houghton G. Can neuropsychological evidence inform connectionist modelling? Analyses of spelling. Language and Cognitive Processes 1995; 10: 195-225.

Tainturier MJ, Caramazza A. A case study of a graphemic buffer impairment affecting pseudoword reading. Paper presented at TENNET meeting, Montreal, Canada, May 1994.

Tainturier MJ, Caramazza A. The status of double letters in graphemic representations. Journal of Memory and Language 1996; 35: 53-73.

Ward J, Romani C. Serial position effects and lexical activation in spelling: Evidence from a single case study. Neurocase 1998; 4: 189-206.

Ward J, Olson A, Romani C. Competitive queuing and spelling: Modelling acquired dysgraphia. In: Heinke D, Olson A, Humphreys GW, editors. Connectionist models in cognitive science. London: Springer-Verlag, 1998: $25-41$.

Wing AM, Baddeley AD. Spelling errors in handwriting: A corpus and a distributional analysis. In: Frith U, editor. Cognitive processes in spelling. London: Academic Press, 1980: 251-85.

Received on $20 \mathrm{March}, 2000$; resubmitted on $6 \mathrm{July}, 2000$; accepted on 1 August, 2000

\section{Serial order effects in spelling errors: evidence from two dysgraphic patients}

\section{N. O. Schiller, J. A. Greenhall, J. R. Shelton and A. Caramazza}

\section{Abstract}

This study reports data from two dysgraphic patients, $\mathrm{TH}$ and $\mathrm{PB}$, whose errors in spelling most often occurred in the final part of words. The probability of making an error increased monotonically towards the end of words. Long words were affected more than short words, and performance was similar across different output modalities (writing, typing and oral spelling). This error performance was found despite the fact that both patients showed normal ability to repeat the same words orally and to access their full spelling in tasks that minimized the involvement of working memory. This pattern of performance locates their deficit to the mechanism that keeps graphemic representations active for further processing, and shows that the functioning of this mechanism is not controlled or 'refreshed' by phonological (or articulatory) processes. Although the overall performance pattern is most consistent with a deficit to the graphemic buffer, the strong tendency for errors to occur at the ends of words is unlike many classic "graphemic buffer patients' whose errors predominantly occur at word-medial positions. The contrasting patterns are discussed in terms of different types of impairment to the graphemic buffer.

\section{Journal}

Neurocase $2001 ; 7: 1-14$

\section{Neurocase Reference Number:}

0210

\section{Primary diagnosis of interest}

Left hemisphere stroke

\section{Author's designation of case}

$\mathrm{TH}$

PB

\section{Key theoretical issue}

- Dysgraphia, effects of serial order

Key words: neuropsychology; dysgraphia; serial order effects in spelling; graphemic buffer disorder

\section{Scan, EEG and related measures}

CT scan, vascular MRI scan

\section{Standardized assessment}

The Johns Hopkins University Dysgraphia Battery, the Philadelphia Naming Test

\section{Other assessment}

Self-contained spelling tests

\section{Lesion location}

- TH: infarct in the territory of the left middle cerebral artery

- PB: superior/parietal left middle cerebral artery territory infarction

\section{Lesion type}

TH: left hemisphere stroke

$\mathrm{PB}$ : subarachnoid haemorrhage

\section{Language}

English 